\title{
Mobilidade Urbana Sustentável: um ensaio sobre o conceito
}

\author{
Graziela Bohusch ${ }^{*}$ \\ Luiz Fernando Scheibe**
}

\section{Resumo}

Este artigo objetiva discutir o conceito de mobilidade sustentável. Primeiramente é revisada a abordagem e interpretação que hoje é comumente dada ao tema, manifestada em grande escala por agências internacionais que têm preocupação com a questão ambiental e presente em boa parte dos programas públicos federais, estaduais e municipais. Buscando-se aprofundar teoricamente uma definição de mobilidade sustentável, a partir da revisão de outras definições, foi necessário explorar o conceito de sustentabilidade. A partir desses elementos propôs-se um entendimento possível de mobilidade sustentável e buscou-se analisar algumas políticas públicas recentes para esse setor, com o objetivo de compreender se elas se inserem em uma lógica sustentável ou não.

Palavras-chave: Mobilidade urbana; Sustentabilidade; Mobilidade sustentável; Política nacional de mobilidade urbana.

An essay on the concept of Urban Sustainable Mobility

\footnotetext{
* Geógrafa, Mestranda do Programa de Pós-Graduação em Geografia da UFSC (grazielabohusch@gmail.com).

*** Professor aposentado do Departamento de Geociências e Voluntário junto aos Programas de Pós-Graduação em Geografia (PPGG) e Interdisciplinar em Ciências Humanas (PPGICH) da UFSC (scheibe2@gmail.com).
}

Geosul, Florianópolis, v. 29, n. 57, p 157-176, jan./jun. 2014 
BOHUSCH, G. \& SCHEIBE, L.F. Mobilidade urbana sustentável: um...

Abstract

This article intends to discuss the concept of sustainable mobility. At first we review the approach and interpretation that is commonly given to this subject by international agencies that have concerns about the environmental issue and by other many federal, regional and local programs. In order to search a definition for sustainable mobility by a theoretical research, based on review of others definitions, it was also necessary to explore the concept of sustainability. From these elements it was proposed a possible understanding to sustainable mobility and we tried to analyze some recent public policies for mobility sector, in order to understand whether they are located in a sustainable logic or not.

Key words: Urban mobility; Sustainability; Sustainable mobility; Urban mobility national politics.

\section{A mobilidade na problemática ambiental}

A mobilidade urbana entrou na agenda da sustentabilidade ambiental tratada predominantemente como "setor de transportes". A inclusão da temática dos transportes, nas discussões acerca da temática ambiental deve-se à contribuição desse setor, principalmente o urbano, para a geração de gases de efeito estufa e consequente contribuição para o aquecimento global, última polêmica lançada nas discussões ambientais. $\mathrm{O}$ tema das mudanças climáticas tem tido muita ênfase por parte de organismos multilaterais, sendo considerado problema ambiental de grande relevância, o que repercute, de certa forma, nas políticas ambientais do Estado brasileiro, como através, por exemplo, da criação da Política Nacional sobre Mudança do Clima em 2009, que mostra como uma alternativa o mercado de capitais, intitulado, neste caso, Mercado Brasileiro de Redução de Emissões (lei federal $n^{\circ} 12.187$, de 2009). Essa repercussão mostra a hegemonia global de uma determinada linha de pensamento sobre a questão 
BOHUSCH, G. \& SCHEIBE, L.F. Mobilidade urbana sustentável: um...

ambiental e a influência exercida por ela, também chamada, eventualmente, de "economia verde".

Scheibe (2009, apud XAVIER, 2011, p.43), observa que a percepção da "crise ecológica" vem mudando através dos tempos. No período pré-1970, destaca o autor, os assuntos eram a guerra fria, a bomba; em 1972, quando da publicação do relatório Limites do Crescimento, a escassez das matérias primas; em 1983, a moda era a $2^{\mathrm{a}}$ Crise do petróleo; em 1987, o assunto passa a ser o buraco da camada de ozônio; 1992, o meio ambiente e a desbiodiversidade; 2002, a preocupação é com a "escassez" da água; 2006, o tema passou a ser o aquecimento global e as mudanças climáticas. O autor, então, questiona: até quando? Qual a próxima moda do "des-envolvimento" sustentável?

Os transportes urbanos, e notadamente a mobilidade, passam, então, a entrar em cena como causa de preocupação ambiental porque o mote da vez seria o aquecimento global, com o qual teria estreita relação de causalidade.

Sem entrar no mérito da discussão sobre a possível parcela de contribuição antropogênica para as causas das mudanças climáticas globais, que vêm sendo abordadas por inúmeros trabalhos, o fato já empiricamente perceptível e comprovado é que o estado atual da organização da mobilidade urbana implica diversos problemas em uma escala local, que já afetam o ambiente urbano e a qualidade de vida de seus habitantes, motivo suficiente para ser encarado como um problema ambiental, de forma estrita e ampla.

O discurso sobre as mudanças climáticas, nela incluído o "aquecimento global", que ganhou repercussão em órgãos multilaterais, destaca a emissão de gases provenientes da combustão de combustíveis fósseis como o principal agente do processo. O Painel Intergovernamental para Mudanças Climáticas IPCC (2007) aponta o dióxido de carbono, oriundo principalmente do uso de combustíveis fósseis, como o principal contribuinte, dentre os gases de feito estufa, para as mudanças climáticas (Figura 1). O relatório alerta que, a depender das atuais políticas de 
BOHUSCH, G. \& SCHEIBE, L.F. Mobilidade urbana sustentável: um...

mitigação dos efeitos das mudanças climáticas e com as práticas atuais de desenvolvimento sustentável a que elas levam, as emissões mundiais de gases de efeito estufa seguirão aumentando nos próximos decênios (IPCC, p.7). Na projeção de emissões realizada com horizonte 2030, o IPCC (2007) supõe que os combustíveis fósseis mantenham sua posição dominante no conjunto mundial de fontes de energia.

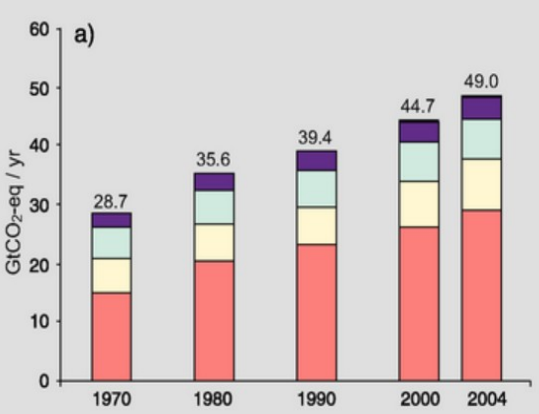

$\square \mathrm{CO}_{2}$ from fossi fuel use and other sources

$\square \mathrm{CH}_{4}$ from agriculture, waste and energy $\square \mathrm{CO}_{2}$ from deforestation, decay and peat $\square \mathrm{N} 2 \mathrm{O}$ from agriculture and others $\quad \square \mathrm{F}$-gases

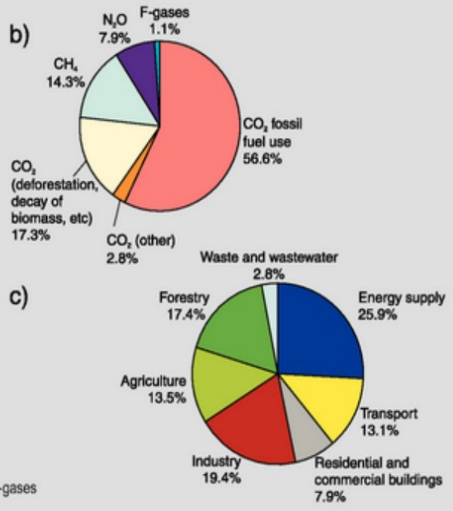

Figura 1: Emissões anuais globais de gases estufa antropogênicos. Fonte IPCC (2007).

A relevância do setor de transportes para o tema das mudanças climáticas e consequentemente para a questão ambiental, segundo a visão dos organismos multilaterais, deve-se à contribuição desse setor para as emissões de gases de efeito estufa. A Comissão de Desenvolvimento Sustentável (2011) do Programa das Nações Unidas para o Meio Ambiente alerta para o fato de o setor de transportes ser o que mais cresce em termos de contribuição de emissão de $\mathrm{CO}_{2}$, para o qual contabiliza $25 \%$ da energia relacionada às emissões, da qual 95\% seria proveniente de combustíveis fósseis. $\mathrm{O}$ transporte rodoviário, segundo a Comissão, contribui para mais da metade da poluição do ar e para mais de $80 \%$ da poluição urbana do ar em algumas cidades. 
BOHUSCH, G. \& SCHEIBE, L.F. Mobilidade urbana sustentável: um...

Observa-se que o transporte como problemática ambiental entrou em evidência após o anúncio do aquecimento global e das mudanças climáticas. No entanto é dado pouco enfoque, por estes organismos, a outros problemas ambientais (em seu conceito mais amplo) também relacionados ao transporte, como a impermeabilização dos solos (pavimentação), poluição hídrica (por meio da contaminação por produtos químicos), desmoronamento de encostas (geração de áreas de instabilidade no solo), inundações, supressão da vegetação, retilinização de rios e córregos, acidentes com seres humanos e com animais, geração de resíduos sólidos (como restos de pneus), degradação urbana das cidades, prejuízos às relações de convivência humana e segregação espacial. Nota-se que o termo sustentável, na abordagem dada por esses organismos, está associado a uma concepção de ambiente físico com bastante e quiçá restrito enfoque à poluição atmosférica. Ao considerarmos que o termo "sustentabilidade" é amplamente discutido na literatura científica e que seu significado já atingiu conotações mais abrangentes, ao levar em conta, por exemplo, as questões sociais também como ambientais, observa-se um pronunciado reducionismo na abordagem desses organismos em comparação a outras definições que consideram o ambiente de forma mais ampla e complexa.

\section{A Sustentabilidade como Conceito e como Intenção}

A revisão deste conceito apoia-se em três autores que tratam do tema da sustentabilidade. Antes de partir para a discussão do que poderia ser uma mobilidade sustentável é importante, primeiramente, entender o que é sustentabilidade, ou pelo menos conhecer a polêmica que envolve esse conceito. Os três autores abordam o tema sob diferentes aspectos, mas têm semelhanças quanto à linha crítica de pensamento.

Diegues (1992) critica o Relatório Brundtland, para o qual pontua questionamentos que à época já pareciam óbvios, como o de preconizar uma sociedade calcada na cultura ocidental, por 
BOHUSCH, G. \& SCHEIBE, L.F. Mobilidade urbana sustentável: um...

exemplo, e o de reducionismo do ambiente a uma fonte de recursos. Leff (2002) observa que o problema ambiental é derivado de uma racionalidade economicista e mercantilizadora do ambiente. Anos depois, o autor ressalta a dualidade do conceito de sustentabilidade e das estratégias de discurso relacionadas ao seu uso (LEFF, 2010). Por fim, Scheibe (2004) adota um caráter pragmático na utilização do conceito ao colocá-lo, mais do que como um qualificador de ações, como uma intencionalidade diante da realidade posta.

Diegues (1992) critica a concepção de desenvolvimento do Relatório Brundtland como estratégia e instrumento para se chegar a uma melhoria da qualidade de vida da população. Para ele, os conceitos de desenvolvimento - mesmo o chamado de "sustentado", ou "sustentável" - baseiam-se na necessidade de se atingir o grau de "desenvolvimento" atingido pelas sociedades industrializadas. Contraditoriamente, o estilo de desenvolvimento dessas sociedades, baseado em um consumo exorbitante, artificialmente barato e intensivo em recursos naturais, sobretudo aqueles vindos dos países do Terceiro Mundo, é igualmente insustentável a médio e longo prazos. $\mathrm{O}$ autor argumenta que para existir uma sociedade sustentável seria necessária a sustentabilidade ambiental, social e política, como um processo e não como um estágio final. Sustentabilidade incluiria ainda princípios sociopolíticos que seriam, principalmente, a distribuição equitativa da riqueza gerada, a participação da população nas decisões, as liberdades democráticas e a satisfação das necessidades básicas.

Tendo em vista uma concepção de ambiente mais abrangente, que inclua o ser humano em todas as suas peculiaridades sociais e que não o considere apenas um mero utilizador dos recursos do meio físico, seria, portanto, necessário ampliar a concepção de "sustentável". Nesse sentido, carimbar (ou "maquiar" - DIEGUES, 1992) de sustentáveis ações ou intervenções que poluem menos seria reduzir o ambiente a apenas 
BOHUSCH, G. \& SCHEIBE, L.F. Mobilidade urbana sustentável: um...

uma parte dele. Qual seria, então, esse conceito de sustentável? Sustentável em quê?

Para Leff (2010), a disseminação da ideia de sustentabilidade veio acompanhada de uma saturação do seu sentido, e com ela uma banalização e também perversão do seu conceito. Argumenta que, além de estar ocorrendo um esvaziamento do sentido de sustentabilidade, devemos compreender este processo como efeito de um desvio e ocultamento por parte dos que não estão interessados em acreditar no sentido da sustentabilidade e tentam seguir desconhecendo as leis e limites da natureza. Para o autor, tratar-se-ia de compreender que a construção da sustentabilidade se produz em um jogo de estratégias discursivas que são, ao final, estratégias de poder do saber e que levam a uma confrontação de sentidos teóricos, políticos, éticos dos conceitos.

Scheibe (2004) questiona: sustentabilidade para quem? Para preservar a ideia romântica da natureza bucólica imaculada? Não, o autor argumenta que, se a natureza está em constante mutação ao longo dos tempos, sendo que as formas, o solo e a cobertura vegetal resultam da contínua interação das forças endógenas do Planeta, responsáveis pelo relevo, com os agentes externos, especialmente ligados ao clima, o que caracteriza a degradação ambiental não seria exclusivamente uma modificação, mesmo que violenta, do ambiente natural, mas, basicamente, as consequências na qualidade de vida dos seres humanos, pois dependemos diretamente de nossa relação com o ambiente natural para nele viver: a expressão "meio ambiente" passa a fazer sentido quando tratamos da relação entre a sociedade e este ambiente, o "meio ambiente do homem". Ao seguir a linha desse raciocínio, surte sem sentido a preocupação com o computo geral de gases de efeito estufa na atmosfera global enquanto centros urbanos estão imersos em diversos problemas ambientais gerados pelo atual modelo de produção e reprodução social. A Sustentabilidade, portanto, estaria, no sentido dado pelo autor, diretamente ligada à qualidade de vida 
BOHUSCH, G. \& SCHEIBE, L.F. Mobilidade urbana sustentável: um...

das pessoas. Neste caso, uma cidade sustentável seria a que, dentre outras coisas, proporciona bem estar aos seus cidadãos.

Scheibe (2004) faz também a seguinte reflexão: Sustentável não precisa ser aquilo que necessariamente se autossustenta, um sistema fechado sem alimentação externa. Sustentável deve ser aquilo que se quer manter, perpetuar, como ideal, como projeto, portanto é algo que deve ser alimentado, incentivado e promovido, no interesse da sociedade.

Essa reflexão do autor sobre o "sustentável" ser aquilo que deve ou merece ser sustentado (a partir de um interesse em fazer com que aconteça), e não aquilo que se sustenta sozinho, é um convite à reflexão sobre o papel do Estado, representado por suas instituições e ações, na promoção de políticas que tenham como objetivo promover situações que trazem benefícios à sociedade. Diferentemente das estratégias de mercado de desenvolvimento sustentável, que envolvem os chamados "mecanismos de desenvolvimento limpo", onde os benefícios ambientais e sociais decorrentes são dependentes dos interesses de mercado (inclusive negociáveis, como créditos de carbono), essa noção destaca a responsabilidade social, através de ações do Estado, em fazer com que o "sustentável" aconteça, não pelo fato de autossustentar-se economicamente, mas pelo interesse comum de que ocorra.

\section{Metodologia}

As etapas de elaboração deste trabalho consistiram na revisão teórica do conceito de sustentabilidade e na análise do significado dado ao termo por diferentes autores e atores sociais. $\mathrm{O}$ discurso sobre a sustentabilidade de órgãos multilaterais é analisado como se esses fossem não somente autores, mas também atores sociais por materializarem no espaço, através de ações, o seu discurso acerca da questão.

Foram revisados autores que analisaram criticamente o conceito de "desenvolvimento sustentável" e de sustentabilidade em períodos históricos diferentes. 
BOHUSCH, G. \& SCHEIBE, L.F. Mobilidade urbana sustentável: um...

A seguir buscou-se verificar qual a relevância da interpretação do conceito de sustentabilidade para a construção do conceito "mobilidade sustentável" e que repercussões práticas pode-se esperar de determinadas conotações dadas ao tema. Por fim, após se construir uma interpretação possível do conceito de mobilidade sustentável a partir da revisão dos autores trabalhados e considerando que representam uma evolução crítica sobre o conceito a partir de um amadurecimento teórico, analisa-se as políticas de mobilidade recentes no intuito de avaliá-las quanto à sua sustentabilidade.

\section{A mobilidade sustentável - ensaio de aplicação do conceito}

Após a discussão sobre a relação da mobilidade com a produção do espaço urbano, entende-se que ela é produto e produtora da cidade, numa relação dialética. Compreende-se que nesse ambiente urbano as ações e intencionalidades de um paradigma hegemônico deixam rugosidades, heranças fisicoterritoriais e socioterritoriais - viadutos, rodovias urbanas, rios urbanos retilinearizados, e que, de certa forma, também condicionam a vida nesse ambiente, promovem fraturas sócioespaciais e estão diretamente ligadas à qualidade de vida das pessoas que nele vivem. A mobilidade é dinâmica, não é só produto das relações que se dão no território, mas também é produtora de espacialidades e campo de disputa entre atores.

Posteriormente observou-se que a mobilidade aliada à questão ambiental é tratada sob o enfoque do ambiente físico e de sua contribuição para a poluição atmosférica e para o aquecimento global, notadamente representada, para as agências internacionais, como o setor de transportes. E, por último, revisou-se o conceito de sustentabilidade como etapa para se construir o entendimento desse conceito relacionado ao de mobilidade.

O esforço feito até agora permitiu levantar subsídios teóricos para uma interpretação possível do conceito de mobilidade sustentável. Assim, considera-se que: 
BOHUSCH, G. \& SCHEIBE, L.F. Mobilidade urbana sustentável: um...

- Deve ser entendido como produto e produtor do espaço geográfico e imbricado das relações de poder a ele inerentes;

- Não deve ser reduzido aos aspectos do meio físico, portanto deve considerar também os aspectos sociais relativos a uma concepção de ambiente que considera o ambiente humano, sendo o indicador recomendado a qualidade de vida das pessoas;

- A palavra "sustentável", do conceito "mobilidade sustentável", não deve ser entendida apenas como um adjetivo, um qualificador, mas também como uma intenção, trazendo para seu significado uma ideia de "mobilidade que merece ser sustentada" em prol de um bem comum.

Diante desse conceito possível de mobilidade sustentável, que serve, metaforicamente, como "lente" teórica para uma leitura da realidade, pode-se analisar alguns fatos:

Em janeiro de 2012 o Governo Federal sancionou a Política Nacional de Mobilidade Urbana (lei federal $n^{\circ}$ 12587), que entrou em vigor no mês de abril de 2012, após 17 anos de tramitação no Congresso Nacional. É, segundo seu texto, instrumento da política de desenvolvimento urbano e objetiva a integração entre os diferentes modos de transporte e a melhoria da acessibilidade e da mobilidade das pessoas e de cargas no território do Município, bem como contribuir para o acesso universal à cidade. $\mathrm{O}$ processo histórico que contribuiu para a sua formulação remonta à criação do Ministério das Cidades em 2003. Até então, após a extinção da Empresa Brasileira de Transportes Urbanos (EBTU), o planejamento e regulação desse setor no âmbito do governo federal havia ficado enfraquecido e disperso em vários órgãos.

Maricato (2006, p.219) considera que a criação do Ministério das Cidades e a formulação da Política Nacional de Desenvolvimento Urbano com participação social, que buscou definir políticas gerais e setoriais integradas de habitação, 
BOHUSCH, G. \& SCHEIBE, L.F. Mobilidade urbana sustentável: um...

saneamento ambiental e transportes para as cidades, é um forte impulso para incluir a questão urbana na agenda política brasileira. A autora avalia que nesse processo houve a criação de paradigmas inovadores que estão disputando o espaço de referência para as ações do Estado ou da sociedade na busca de democracia e justiça social.

Gomide (2008) resgata o histórico do processo que envolveu o projeto de lei de diretrizes da Política Nacional de Mobilidade Urbana. Segundo o autor, a motivação para a formulação de um novo marco regulatório para os transportes urbanos teve como um impulsor o diagnóstico feito pela SEMOB - Secretaria de Mobilidade Urbana do Ministério das Cidades, em 2006, intitulado "Proposta de barateamento das tarifas do transporte público urbano", que teria identificado como principal causa para o problema a falta de planejamento eficiente do setor, incluindo má administração das redes, não integração dos serviços, desrespeito aos princípios da legislação de concessões e permissões de serviços públicos, devido à ausência de licitações competitivas para delegação da operação do transporte coletivo e ausência de mecanismos de fixação e reajustes de tarifas com metodologias transparentes e com bons fundamentos técnicos, tanto para o aumento do volume de investimentos nos serviços quanto para incentivar ganhos de eficiência com reflexos positivos nas tarifas, e consequente repercussão nos custos. O autor compara o diagnóstico com o histórico de propostas de soluções para o problema do custo operacional do transporte urbano, emanadas de alguns atores políticos com o objetivo de redução do custo operacional do transporte urbano e necessária repercussão na redução das tarifas praticadas pelos municípios. Essas propostas incluíam basicamente subvenções econômicas e desoneração tributária, dentre as quais a redução do preço do combustível e a desoneração dos encargos sociais. $O$ autor avalia, por fim, corroborando para o diagnóstico da SEMOB, que tal tipo de subvenção por parte do governo federal não seria economicamente sustentável a longo prazo, por incentivar a ineficiência do serviço. 
BOHUSCH, G. \& SCHEIBE, L.F. Mobilidade urbana sustentável: um...

Em 2004 fora publicada pelo Ministério das Cidades uma série de edições, denominada Cadernos MCidades, que tinha como objetivo promover o debate das propostas de políticas setoriais, incluindo Transporte e Mobilidade Urbana, elaboradas no âmbito do Conselho das Cidades, que fora eleito em conferência nacional, em outubro de 2003, após um processo de conferências menores realizadas em 3.457 municípios do país e que visava estabelecer princípios e diretrizes da Política Nacional de Desenvolvimento Urbano. Esses documentos eram preparatórios para a II Conferência Nacional das Cidades, em 2005. Dentre os princípios emanados da I Conferência Nacional das Cidades, que serviriam de referência para a Política Nacional de Desenvolvimento Urbano, estavam os de "sustentabilidade financeira e socioambiental da política urbana", "direito à cidade para todos" e "direito à mobilidade, transporte público e ao trânsito seguro". A II Conferência incluiu dentre as diretrizes para a PNDU a "integração das políticas de habitação, saneamento ambiental, transporte e mobilidade, planejamento e gestão do solo urbano".

O caderno de diretrizes para a Política Nacional de Mobilidade Urbana Sustentável, publicado em 2004 definia mobilidade como

[...] o resultado de um conjunto de políticas de transporte e circulação que visa proporcionar o acesso amplo e democrático ao espaço urbano, através da priorização dos modos não-motorizados e coletivos de transporte, de forma efetiva, que não gere segregações espaciais, socialmente inclusiva e ecologicamente sustentável. Ou seja: baseada nas pessoas e não nos veículos. (Ministério das Cidades, 2004, p. 13, 14)

O caderno faz um diagnóstico da situação do transporte coletivo no Brasil e já apresentava, à época de sua publicação, conclusões similares ao diagnóstico elaborado posteriormente, no ano de 2006, pela SEMOB (GOMIDE, 2008). 
BOHUSCH, G. \& SCHEIBE, L.F. Mobilidade urbana sustentável: um...

Já a Política Nacional de Mobilidade Urbana, lei 12587/12, perde o adjetivo "sustentável". Segundo seu texto, mobilidade pode ser definida como "condição em que se realizam os deslocamentos de pessoas e cargas no espaço urbano". Todavia, apesar de ser uma referência normativa para a implementação de políticas voltadas à mobilidade urbana, suas diretrizes e objetivos ainda carecem de regulamentação.

IPEA (2012, p.6), ao avaliar a nova lei, considera que ela preserva quase a totalidade dos princípios e das diretrizes da Política Nacional de Mobilidade Urbana Sustentável, formulados pelo Ministério das Cidades em 2004, na ocasião de reunião do Conselho das Cidades. Afirma que, até a sua promulgação, a capacidade desses princípios e diretrizes de influenciar a política municipal de transporte urbano ficava apenas restrita à capacidade do governo federal de impor algum tipo de condicionalidade ao financiamento e apoio para as políticas locais de transportes urbanos Um aspecto positivo seria o de que esta lei passa a fornecer segurança jurídica para que os municípios possam adotar medidas ou instrumentos de priorização aos meios nãomotorizados e coletivos de transporte em detrimento ao individual, como no caso da restrição e controle de acesso e circulação de veículos em locais e horários pré-determinados do artigo 23 da lei, e que também podem ser contestados caso não o façam. Todavia, sabe-se que os municípios já têm poderes para fazer restrições desse tipo, através do poder que têm de regulação do uso do espaço urbano e de instrumentos como a própria constituição, o código de trânsito, os planos diretores municipais e o zoneamento urbano.

Um aspecto salientado como negativo pelo IPEA (2012, p. 14), e que gera bastante contradição pela existência de amplo debate popular e diagnóstico precedente à promulgação da lei, foi o veto ao seu artigo $8^{\circ}$, que determinava a criação de fontes específicas de recursos financeiros para financiar as gratuidades do sistema de transporte. 
BOHUSCH, G. \& SCHEIBE, L.F. Mobilidade urbana sustentável: um...

“Art. $8^{\circ} \S 1^{\circ}$ A concessão de benefícios tarifários a uma classe ou coletividade de usuários nos serviços de transporte público coletivo deverá ser custeada com recursos financeiros específicos previstos em lei, sendo vedado atribuir o referido custeio aos usuários do respectivo serviço público." BRASIL (2012b, p.1, mensagem de veto)

A mensagem de veto que justificava a não-manutenção afirmava o seguinte:

"O $\S 1^{\circ}$ restringe as hipóteses de gestão das tarifas dos serviços de transporte público coletivo, o que pode acarretar a necessidade de aporte maior de recursos orçamentários e financeiros pelos entes federados, além de ser contraditório com $\S 5^{\circ}$ do art. $9^{\circ}$ do projeto."

BRASIL (2012b, p.1, mensagem de veto)

$\mathrm{O} \S 5^{\circ}$ do art. $9^{\circ}$ da lei 12.587 , que institui a PNMU, ao contrário do seu vetado Art. $8^{\circ}$, que criava uma regra de proteção ao usuário e à própria manutenção econômica do sistema, terminando com o ciclo vicioso de aumento das tarifas - evasão e exclusão de usuários - concessão de benefícios - encarecimento das tarifas, permite, por outro lado, maior flexibilidade na concessão dos subsídios. Na prática, fica a critério do poder concedente municipal decidir sobre a existência ou não de subsídio e ainda escolher os mecanismos para o seu financiamento, inclusive com a liberdade de deixar como está, na medida em que admite subsídios cruzados intrassetoriais. Segundo este parágrafo,

Caso o poder público opte pela adoção de subsídio tarifário, o déficit originado deverá ser coberto por receitas extratarifárias, receitas alternativas, subsídios orçamentários, subsídios cruzados intrassetoriais e intersetoriais provenientes de outras categorias de beneficiários dos serviços de transporte, dentre outras fontes, instituídos pelo poder público delegante.

BRASIL (2012, Art. $\left.9^{\circ}, \S 5^{\circ}\right)$ 
BOHUSCH, G. \& SCHEIBE, L.F. Mobilidade urbana sustentável: um...

IPEA (2012, p.14) considera que esse veto traz um caráter de regressividade à política tarifária, além de deixar o setor sem mecanismos permanentes de financiamento da infraestrutura, problema já apontado quando da reunião do Conselho das Cidades para definição das diretrizes da então Política Nacional de Mobilidade Sustentável (2004, p.29).

Observa-se, com essa ação, a manutenção da postura do Estado em delegar ao cidadão a responsabilidade pela solução do problema de sua locomoção, na medida em que os usuários, entre si, têm de ratear o custo de direitos garantidos, por lei, concedidos pelo Estado, mas que não são promovidos diretamente por ele, através de subsídios governamentais específicos. O problema da falta de qualidade no transporte coletivo tem repercussões nas externalidades geradas pelo trânsito em geral. Os usuários do transporte coletivo buscam resolver seu problema de imobilidade migrando para outros modos de transporte, como para a motocicleta e para o automóvel particular, cuja aquisição é facilitada pelo aumento do crédito nos últimos anos e por incentivos fiscais como a redução do IPI. Segundo MANO (2012, p.1) a supremacia do transporte individual cria sérios problemas de mobilidade nas grandes cidades brasileiras. A autora afirma que nos últimos dez anos, a frota nacional de veículos cresceu $119 \%$, segundo dados do Departamento Nacional de Trânsito e que o país tem média de um carro para cada 2,94 habitantes.

Diante dessa realidade e com base no conceito de mobilidade sustentável construído nos capítulos anteriores, observa-se que o setor de mobilidade urbana não se direciona para um caminho da sustentabilidade. Entendendo-se "sustentável" como "aquilo que deve ser sustentado pela sociedade como um todo em prol de um benefício comum" observa-se ainda a persistência de um outro paradigma, no qual sustentabilidade seria apenas um "adjetivo verde”. O veto ao Art. $8^{\circ}$ e a flexibilização quanto à concessão de subsídios, a critério de cada município, mostra que não há ainda uma iniciativa de se "sustentar" uma política de mobilidade que beneficie a sociedade na sua integralidade. 
BOHUSCH, G. \& SCHEIBE, L.F. Mobilidade urbana sustentável: um...

Ao se pensar sustentabilidade e mobilidade urbana, considera-se que não só a sustentabilidade do ponto de vista econômico direto deve ser levada e conta. Os poderes concedentes muito se preocupam com a sustentabilidade econômica dos sistemas de transporte, que eles se paguem, sejam superavitários, que todo o seu custo seja incluído na tarifa, para que os próprios usuários financiem o custo da sua operação. Deve-se pensar no que a sociedade como um todo quer incentivar e nos custos disso. Assim, por exemplo, práticas como subsídio ao transporte coletivo poderiam ser pensadas não como resultado de um sistema não sustentável economicamente, mas como incentivo, de toda sociedade, em prol de um ideal de interesse comum e que trará benefícios a ela, externalidades positivas que também podem ser consideradas como vantagens econômicas.

A redução do IPI, que chegou a até $100 \%$ para carros de 1000 cilindradas, motivada pela redução das vendas do setor automobilístico em razão da crise econômica, gera externalidades para a mobilidade urbana, como congestionamentos, poluição atmosférica e acidentes. Segundo nota técnica do IPEA $(2009$, p.4) a desoneração do IPI teria contribuído com 13,4\% dos veículos vendidos ao longo do primeiro semestre de 2009. Dessa forma, com uma motivação econômica, a sociedade como um todo "sustentou" uma política para recuperação nas vendas do setor.

\section{Conclusão}

Não se pode dizer que a mobilidade urbana, nas condições atuais, possa ser considerada como "sustentável", à luz do conceito aqui forjado. Ou seja, a mobilidade paga o preço da política econômica de redução do IPI e aumento do financiamento para veículos, paga o preço também de programas de habitação deslocados do planejamento de transporte, que tendem a favorecer a expansão da cidade. Verifica-se, dentro da própria Secretaria de Mobilidade Urbana, a existência de programas direcionados para o setor de transportes ou de mobilidade em geral, e que, não por 
BOHUSCH, G. \& SCHEIBE, L.F. Mobilidade urbana sustentável: um...

menos, são os que mais aportam recursos e que estão relacionados a um objetivo anterior, que é econômico, como o Programa de Aceleração do Crescimento - PAC e sua modalidade para o setor, o PAC da Mobilidade. Dentro do que se pensou aqui por sustentabilidade, não haveria uma inversão de prioridades?

O lançamento do PAC Mobilidade Médias Cidades anunciou, em 2012, a disponibilização de R\$ 7 bilhões para projetos de infraestrutura de transporte público coletivo em cidades com população entre $250 \mathrm{mil}$ e $700 \mathrm{mil}$ habitantes. Segundo o noticiado (BRASIL, 2012), as obras do PAC Mobilidade Médias Cidades deverão ter ritmo acelerado, pois fazem parte do Regime Diferenciado de Contratações (RDC) e será priorizada a escolha de projetos em fase avançada de elaboração para permitir que as obras sejam executadas o mais rápido possível. Apesar da possibilidade de destinar parte dos recursos para projetos, boa parte desses municípios não possui Planos de Mobilidade, o que dificulta a integração com outros setores, como habitação e saneamento, e pode desencadear nessas cidades problemas comuns aos das cidades grandes. Além disso, esse programa do governo federal não financia ciclovias, o que pode ser considerado um retrocesso e contradição com as diretrizes da Política Nacional de Mobilidade Urbana, publicada no mesmo ano.

Tais fatos exemplificam a necessidade que há de uma mudança de paradigma no conceito de mobilidade sustentável, que deve efetivamente passar pela priorização aos transportes coletivos, ao andar a pé e ao andar em bicicleta, ao uso racional do espaço urbano e à justiça social, para além do discurso e por uma outra racionalidade na produção do espaço urbano.

$\mathrm{O}$ enfoque excessivo nas mudanças climáticas força que não seja dada à sustentabilidade uma interpretação diferente de um sentido estrito, na qual o enfoque sobre os aspectos físicos da natureza sobrepujem os aspectos sociais, os quais, por sua vez, são os fatores que mais contribuem para o sustento de um tipo de mobilidade que seja viável a longo prazo, socialmente inclusiva, justa, igualitária e cujo objetivo seja a qualidade de vida e o bem estar das pessoas. 
BOHUSCH, G. \& SCHEIBE, L.F. Mobilidade urbana sustentável: um...

\section{Referências bibliográficas:}

BRASIL. PAC Mobilidade Médias Cidades vai melhorar as condições de vida da população, afirma Dilma. Blog do Planalto em 19 de julho de 2012. Disponível em: http://blog.planalto.gov.br/pac-mobilidademedias-cidades-vai-melhorar-as-condicoes-de-vida-da-populacao-afirmadilma/. Acesso em setembro de 2012.BRASIL. Lei 12.587 de 3 de janeiro de 2012. Dispõe sobre a Política Nacional de Mobilidade Urbana. Disponível em http://www.planalto.gov.br/ccivil_03/_ato20112014/2012/lei/112587.htm. Acesso em 10 de agosto de 2012.

COMISSÃO DE DESENVOLVIMENTO SUSTENTÁVEL DAS NAÇÕES UNIDAS (2011). United Nation Environment Programme. Disponível em http://www.un.org/esa/dsd/resources/res_pdfs/csd-19ipm/1March/AM/UNEP.pdf. Acesso em 10 de junho de 2012.

\section{DIEGUES (1992). Desenvolvimento Sustentável ou Sociedades} Sustentáveis: da crítica dos modelos aos novos paradigmas. Revista São Paulo em Perspectiva, São Paulo, v.06/ nº.1-2.

GOMIDE, A. A. (2008). Agenda Governamental e o Processo de Políticas Públicas: O Projeto de Lei de Diretrizes da Política Nacional de Mobilidade Urbana. Texto para Discussão n 1334 . Brasília, IPEA Instituto de Pesquisa Econômica Aplicada.

IPEA (2009). Impactos da Redução do Imposto sobre Produtos Industrializados (IPI) de Automóveis. Nota Técnica. Disponível em:http://www.ipea.gov.br/sites/000/2/publicacoes/notastecnicas/notastec nicas26.pdf. Acesso em 14 de agosto de 2012.

LEFF, E. (2002). Epistemologia Ambiental. São Paulo, ed. Cortez.

.(2010). Entrevista: Enrique Leff. Revista Página 22 (Online). São Paulo, ed. 43. Disponível em http://pagina22.com.br/index.php/2010/07/entrevista-enrique-leff/. Acesso em 10 de junho de 2012. 
BOHUSCH, G. \& SCHEIBE, L.F. Mobilidade urbana sustentável: um...

MANO, K. M. (2012). Mobilidade Urbana - O automóvel ainda é prioridade. Revista Desafios do Desenvolvimento, Brasília, v.1, $\mathrm{n}^{\mathrm{o}} 72$, ano $9 . \quad$ Disponível em http://www.ipea.gov.br/desafios/index.php?option=com_content\&view=a rticle\&id=2578: catid=28\&Itemid=23. Acesso em 23 de agosto de 2012.

MARICATO, E. (2006). O Ministério das Cidades e a Política Nacional de Desenvolvimento Urbano. Políticas Sociais acompanhamento e análise, v.12. Disponível em:http://www.ipea.gov.br/sites/000/2/publicacoes/bpsociais/ bps_12/ensaio2_ministerio.pdf. Acesso em 10 de junho de 2012.

MINISTÉRIO DAS CIDADES (2004). Política Nacional de Mobilidade Urbana Sustentável. Cadernos do Ministério das Cidades. Disponível em

http://www.capacidades.gov.br/media/doc/acervo/5a1566905bdf787cb03 85521af19a938.pdf. Acesso em 12 de setembro de 2012

MINISTÉRIO DAS CIDADES (2012). Secretaria Nacional de Transporte e da Mobilidade Urbana - Programas e ações. Disponível em http://cidades.gov.br. Acesso em 23 agosto de 2012.

MINISTÉRIO DAS CIDADES (2012). Diretrizes Gerais Para O Pac 2 Mobilidade Médias Cidades. Disponível em:http://www.cidades.gov.br. Acesso em 14 de agosto de 2012.

MINISTÉRIO DE MINAS E ENERGIA (2011). Balanço Energético Nacional. Brasil. Disponível em http://www.mme.gov.br/mme/menu/todas_publicacoes.html. Acesso em 10 de junho de 2012.

ORGANIZAÇÃO DAS NAÇÕES UNIDAS - ONU (1987). Caderno Nosso Futuro Comum. Disponível em http://www.undocuments.net/ocf-02.htm 
BOHUSCH, G. \& SCHEIBE, L.F. Mobilidade urbana sustentável: um...

PAINEL INTERGOVERNAMENTAL PARA MUDANÇAS

CLIMÁTICAS (2007). Climate Change 2007: Synthesis Report.

Disponível em:

http://www.ipcc.ch/publications_and_data/ar4/syr/es/spms2.html. Acesso em 10 de junho de 2012.

PEREIRA, Mirlei Fachini Vicente. Redes, sistemas de transportes e as novas dinâmicas do território no período atual: notas sobre o caso brasileiro. Soc. nat. (Online). Uberlândia, v. 21, n. 1, abr. 2009. Disponível

emhttp://www.scielo.br/scielo.php?script=sci_arttext\&pid=S198245132009000100008\&lng=pt\&nrm=iso. acesso em 23 ago. 2012. http://dx.doi.org/10.1590/S1982-45132009000100008.

SECRETARIA EXECUTIVA DO CONSELHO DAS CIDADES (2006). Conselho das Cidades - Um exercício de Gestão Democrática. Brasília. Disponível em: http://www.cidades.gov.br/images/stories/ArquivosCidades/ArquivosPDF /Publicacoes/UmExerciciodeGestaoDemocratica.pdf. Acesso em 14 de agosto de 2012.

SCHEIBE, L. F.(2004). Desenvolvimento Sustentável, Desenvolvimento Durável. In: ZAKRZEVSKI, S. B; BARCELOS, B. (Orgs.). Educação Ambiental e Compromisso Social, Erechim, EdiFAPES.

VASCONCELLOS, E. A. (2006). Transporte e meio ambiente: conceitos e informações para análise de impactos. São Paulo: Ed. do autor.

XAVIER, G. N. A. (2011). O Desenvolvimento e a Inserção da Bicicleta na Política de Mobilidade Urbana Brasileira. Tese de doutorado. Florianópolis, Universidade Federal de Santa Catarina.

Recebido em junho de 2013

Aceito em abril de 2014 